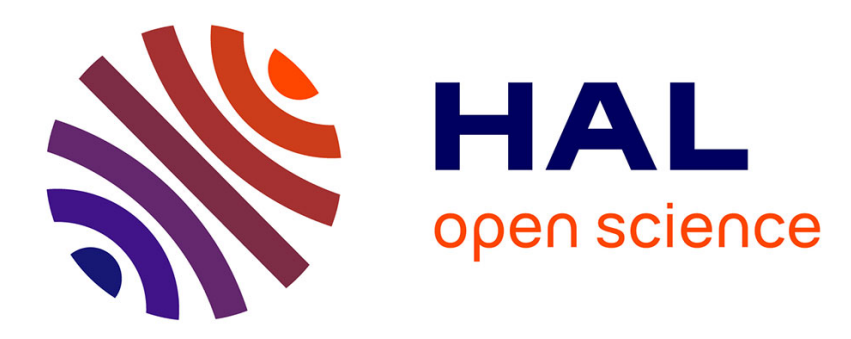

\title{
Application of Olefin Cross-Metathesis to the Synthesis of Biologically Active Natural Products
}

\author{
Joëlle Prunet
}

\section{To cite this version:}

Joëlle Prunet. Application of Olefin Cross-Metathesis to the Synthesis of Biologically Active Natural Products. Current Topics in Medicinal Chemistry, 2005, 5, pp.1559. hal-00085197

\section{HAL Id: hal-00085197 \\ https://hal.science/hal-00085197}

Submitted on 12 Jul 2006

HAL is a multi-disciplinary open access archive for the deposit and dissemination of scientific research documents, whether they are published or not. The documents may come from teaching and research institutions in France or abroad, or from public or private research centers.
L'archive ouverte pluridisciplinaire HAL, est destinée au dépôt et à la diffusion de documents scientifiques de niveau recherche, publiés ou non, émanant des établissements d'enseignement et de recherche français ou étrangers, des laboratoires publics ou privés. 


\section{Application of Olefin Cross-Metathesis to the Synthesis of Biologically Active Natural Products}

Joëlle Prunet

Laboratoire de Synthèse Organique, UMR CNRS 7652, Ecole Polytechnique, DCSO, 91128 Palaiseau,

France

joelle.prunet@polytechnique.fr

\section{Introduction}

Over the past decade, olefin metathesis has become a powerful tool in organic synthesis, and is widely used by chemists in other disciplines as well [1]. Alkene cross-metathesis (CM) (Scheme 1) emerged later than the ring-closing process, as many undesired products such as homodimers often plagued the reaction [2]. The problems to overcome for a successful CM reaction involve the control of chemo- and stereoselectivity, and they have been addressed with success with the development of the more active "second-generation" ruthenium catalysts [Ru]-II [3] and [Ru]-IV [4] (Fig. (1)). A general model to predict the outcome of this reaction was recently reported by Grubbs [5]. One of the advantages of CM over other cross-coupling processes, such as the Stille or the Miyaura-Suzuki reactions, is that no sophisticated coupling partners need to be prepared. Also, as most polar functional groups encountered in advanced synthesis intermediates do not react under CM conditions, retrosynthesis planning involving a metathesis reaction is much easier for complex products.

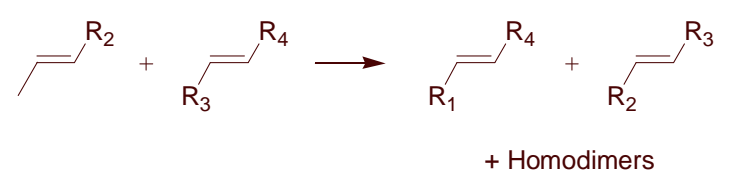

Scheme 1. General cross-metathesis reaction.

This review will be divided in four sections, according to the outcome of the double-bond formed by olefin metathesis, which can be either present in the final product, reduced or engaged in other transformations. Finally, tandem processes involving CM will be detailed.

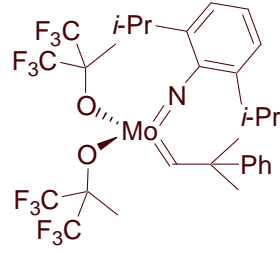

[Mo]

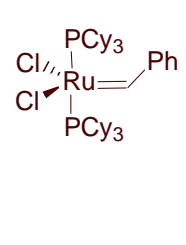

$[R u]-I$

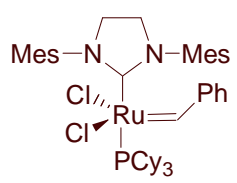

[Ru]-II

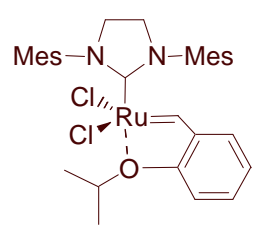

[Ru]-IV

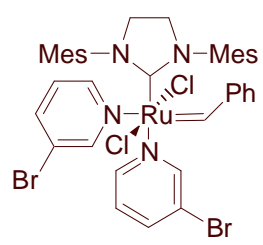

[Ru]-VI

Figure 1. Catalysts commonly used for CM reactions.

\section{CM leading to an olefin present in the final product}

Electron-deficient olefins undergo slow dimerization in the presence of metathesis catalysts, so they are ideal substrates for CM with terminal alkenes [5]. When the electron-poor partner is used in excess, the reaction is very efficient and almost always very diastereoselective in favor of the $E$-isomer. 
The Trost group used such a CM in their synthesis of furaquinocin B, which was extracted from the fermentation broth of Streptomyces sp. KO-3998 and presents activity ranging from cytotoxicity against HeLa S3 and B16 melanoma cells to inhibition of platelet aggregation and coagulation [6]. A large excess of methacrolein (10 equiv) is necessary, because this reagent tends to polymerize under the reaction conditions (Scheme 2).

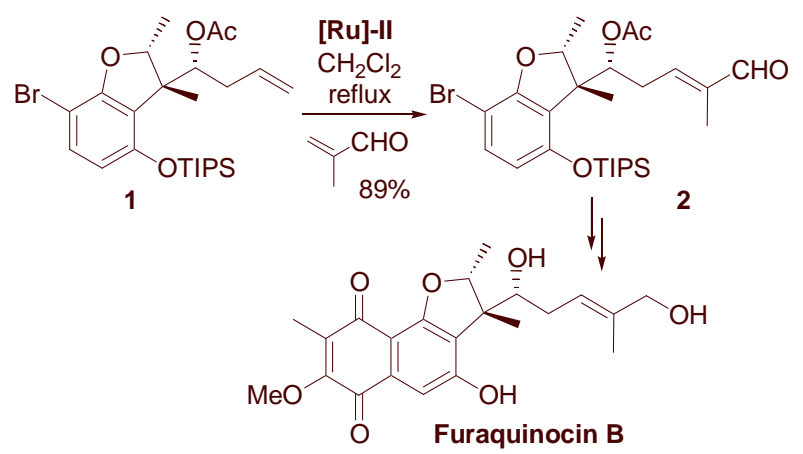

Scheme 2. Synthesis of the side chain of furaquinocin B.

Cossy and BouzBouz designed a retrosynthesis with three $\mathrm{CM}$ reactions between homoallylic alcohols and acrylic derivatives for the construction of the C1-C14 fragment of amphidinol 3 [7]. This compound is a metabolite of the marine dinoflagellate Amphidinium. The first metathesis is straightforward, giving the expected product 4 in 79\% yield with acrolein and carbene [Ru]-IV (Scheme 3). Aldehyde 4 is then transformed into bis-acetate 5 by treatment with the allyltitanium complex $(S, S)-9$ reported by Hafner and Duthaler [8], followed by acetylation. Interestingly, the second CM with acrolein is very chemoselective, and only the homoallylic olefin (respective to the newly formed stereocenter) is reactive. The allylic double bond does not undergo metathesis, probably because the corresponding metallacyclobutane is deactivated by complexation of the ruthenium by the carbonyl moiety of the acetate group. It has been shown on model systems that the same reaction on the corresponding alcohols is not selective [7]. Aldehyde 6 is then transformed into homoallylic acetate 7 as previously, and the C14 carbon is installed by a CM with ethyl acrylate. In each case, the $E / Z$ ratio obtained after metathesis is better than $50: 1$.

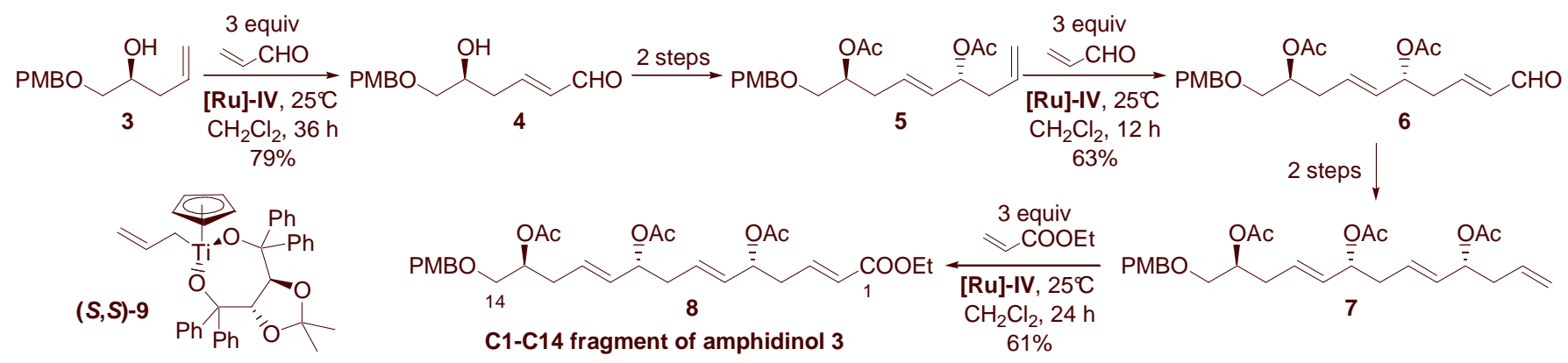

Scheme 3. Synthesis of the C1-C14 fragment of amphidinol 3 involving 3 CM reactions.

The same strategy was employed by Cossy and BouzBouz for the synthesis of the C1-C13, C15$\mathrm{C} 25$ and $\mathrm{C} 27-\mathrm{C} 40$ fragments of tetrafibricin, a potent inhibitor of platelet aggregation through blockage of the GPIIb/IIIa receptor on the platelet surface, which was isolated from Streptomyces neyagawaensis NR0577 [9]. 
CM reactions of homoallylic alcohols are also involved in the syntheses of the enantiomer (10) of a natural product isolated from Raimondia cf monoica (Annonaceae) [10], which possesses leishmaniose activity, and the fragment A of the potent cytotoxic agents cryptophycins (Fig. (2)) [11].

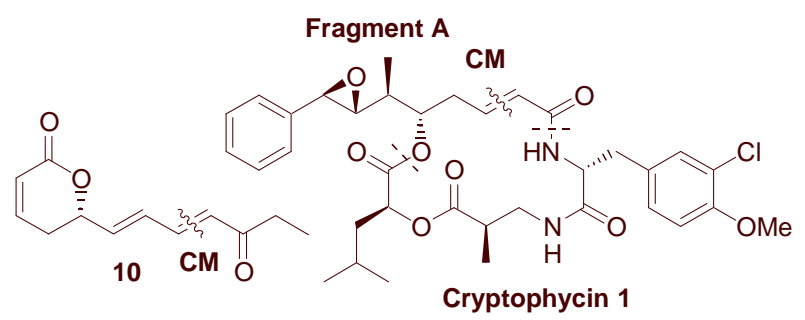

Figure 2. Structures of $\mathbf{1 0}$ and cryptophycin 1.

When two terminal olefins are engaged in cross-metathesis, the reaction is usually not selective unless a large excess of one of the alkenes is used. This type of CM is illustrated in the synthesis of sphingolipids, products involved in signal transduction and in molecular recognition processes in cell membranes. Three members of this class of compounds, D-erythro-sphingosine, D-erythro-ceramide and sphingomyelin have been recently synthesized by Somfai [12], Basu [13] and Katsumara [14] respectively (Scheme 4). When oxazolidinone 11 was treated with 1-pentadecene and catalyst [Ru]-I, no trace of the desired product was observed. Use of complex [Ru]-II furnished compound $\mathbf{1 2}$ in $49 \%$ yield as a 5:1 mixture of $E / Z$ isomers. When 2 equiv of $\mathrm{Ti}(\mathrm{O} i \text {-Pr })_{4}$ was added to the latter reaction, the yield went up to $52 \%$ and the $E / Z$ selectivity to $16: 1$. But the best conditions involved phosphine-free catalyst [Ru]-VI (Fig. (1)) [15]. Before employing the fluorenylmethyloxycarbonyl (Fmoc)-protected amine derivative 13, Basu reacted the corresponding azide with limited success: catalyst [Ru]-II or [Ru]-VI did not furnish any cross-coupled product, and catalyst [Ru]-IV only led to the desired product in $36 \%$ yield. In contrast, the Fmoc carbamate $\mathbf{1 3}$ led to the ceramide precursor $\mathbf{1 4}$ in excellent yield.

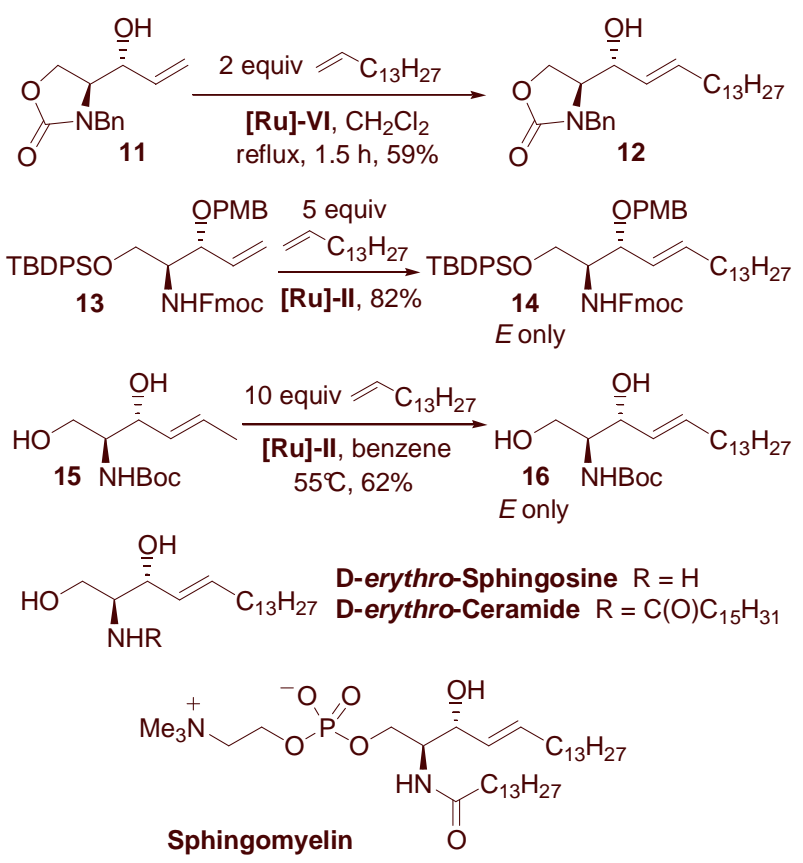

Scheme 4. CM steps in the syntheses of sphingolipids.

Finally, Katsumura investigated diverse protecting groups for the amino alcohol moiety, and found that the substrate which required the lesser amount of ruthenium complex [Ru]-II was diol $\mathbf{1 5}$ where the 
amine is protected by a tert-butoxycarbonyl (Boc) group. With 2 equiv of 1-pentadecene, the yield dropped to $30 \%$, and diol $\mathbf{1 6}$ could not be obtained with the first-generation catalyst [Ru]-I.

In the same way, Sarabia et al. effected a CM between protected allylic alcohol 17 and two different hindered alkenes (used as cosolvents) when studying approaches to bengamides, compounds extracted from sponges of the Jaspidae family which possess antitumor, antibiotic and antihelmintic properties (Scheme 5) [16]. When the alkene was 3-methyl-1-butene, the desired product was obtained in $76 \%$ yield $(E / Z=9: 1)$ using catalyst [Ru]-I, but in the case of 3,3-dimethyl-1-butene, the yield of the corresponding tert-butyl alkene was much lower (only 28\%), proving once again that olefin metathesis is very sensitive to steric hindrance.

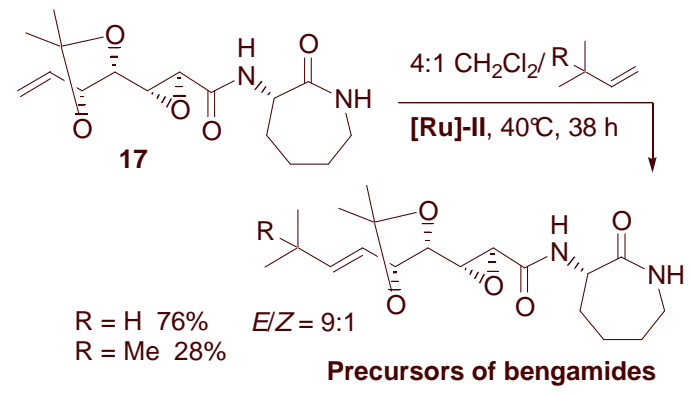

Scheme 5. CM reactions in the syntheses of precursors of bengamides.

$\mathrm{CM}$ reactions between two terminal alkenes are found in the synthesis of highly functionalized natural products. One of the first examples was reported by Hirama et al. when appending the side chain of ciguatoxin to the AB ring system (Scheme 6) [17]. This compound is the main toxin responsible for human intoxication when eating tropical reef fishes, and was isolated in Hawaii from moray eel livers. Use of first-generation Grubbs catalyst [Ru]-I [18] furnished the desired product 19 in only 8\% yield, along with its epimer at C5 20 in 19\% yield. No improvement was obtained when changing the protecting groups of the diol moiety or the concentration of the reaction. Epimerization is thought to occur via intermediate 21, which results from ring-opening of the 7-membered ring of $\mathbf{1 8}$ with the substituted carbene as shown on Scheme 6. In comparison, $\mathbf{1 8}$ was obtained by stereoselective ring-closure metathesis (RCM) from 22 in excellent yield using the same catalyst under mild conditions, which highlights the poor efficiency of first-generation catalysts in $\mathrm{CM}$ reactions.

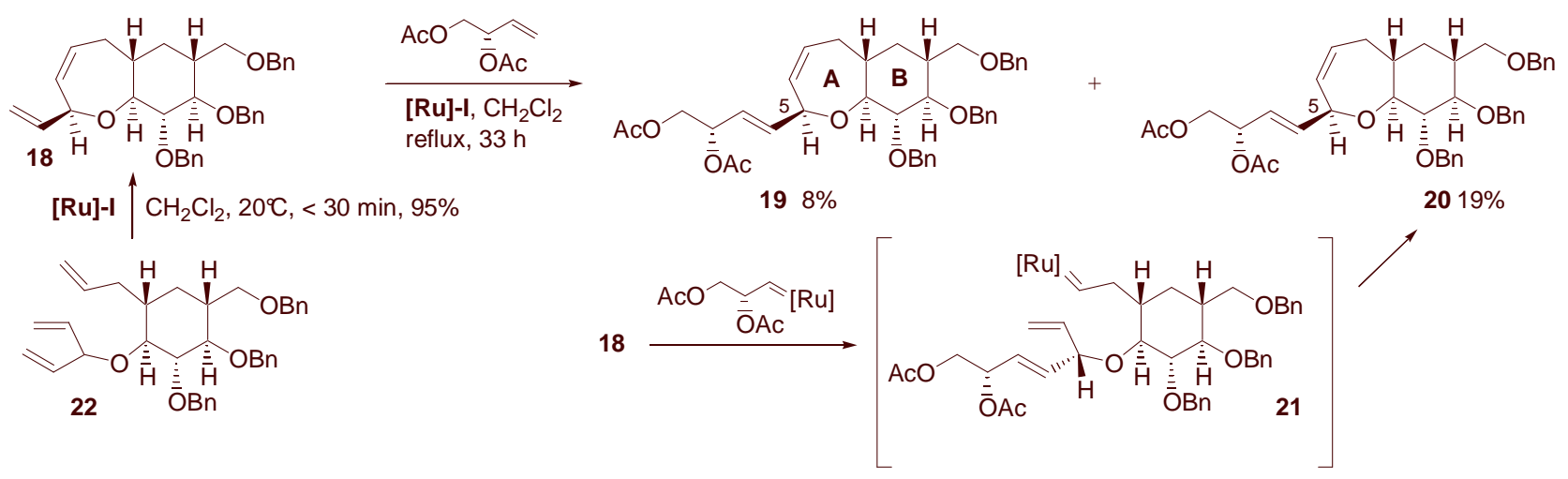

Scheme 6. Construction of the side chain of ciguatoxin.

Nicolaou and co-workers synthesized azaspiracid-1, a poisonous substance which was isolated from the mussel Mytilus edulis [19]. The CM reaction used to install the side chain proceeds in $60 \%$ 
conversion to give the desired product $\mathbf{2 4}$ as a 10:1 separable mixture of $E$ and $Z$ isomers (Scheme 7). The total yield is $95 \%$ when the starting olefin $\mathbf{2 3}$ undergoes three cycles.

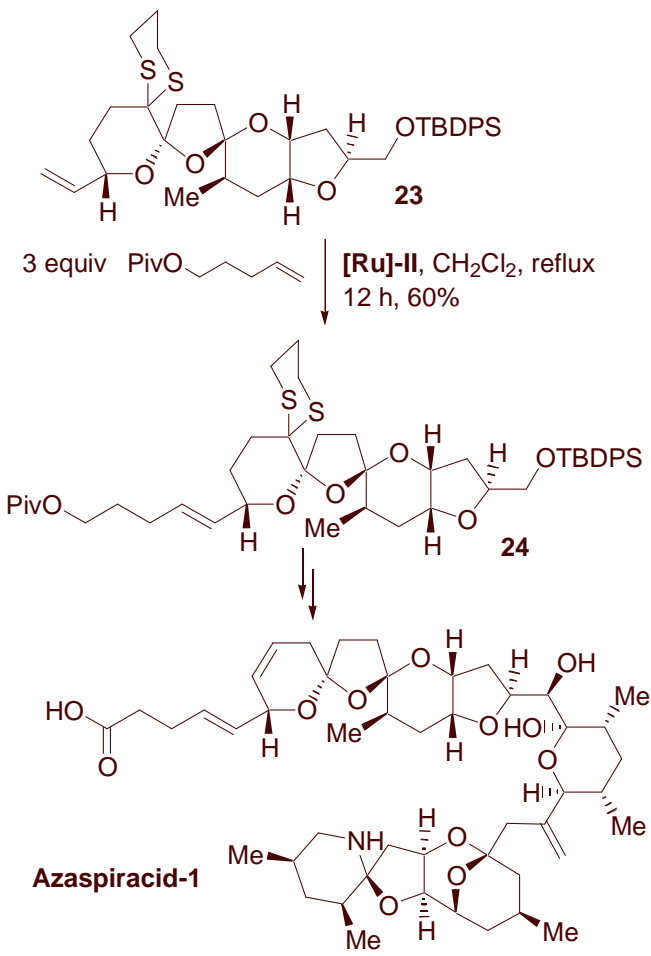

Scheme 7. CM reaction in the synthesis of azaspiracid-1.

Ghosh and Gong assembled with the help of a CM reaction the linear precursor of amphidinolide $\mathrm{W}$, a potent cytotoxic agent against murine lymphoma L1210 cells isolated from the marine dinoflagellate Amphidinolide sp (Scheme 8) [20]. After scanning protecting groups for the allylic alcohol in $\mathbf{2 6}$ and testing different catalysts, he found that the allylic acetate and complex [Ru]-II gave the optimum result, and compound 27 was obtained in $85 \%$ yield $(E / Z$ ratio $=11: 1)$.
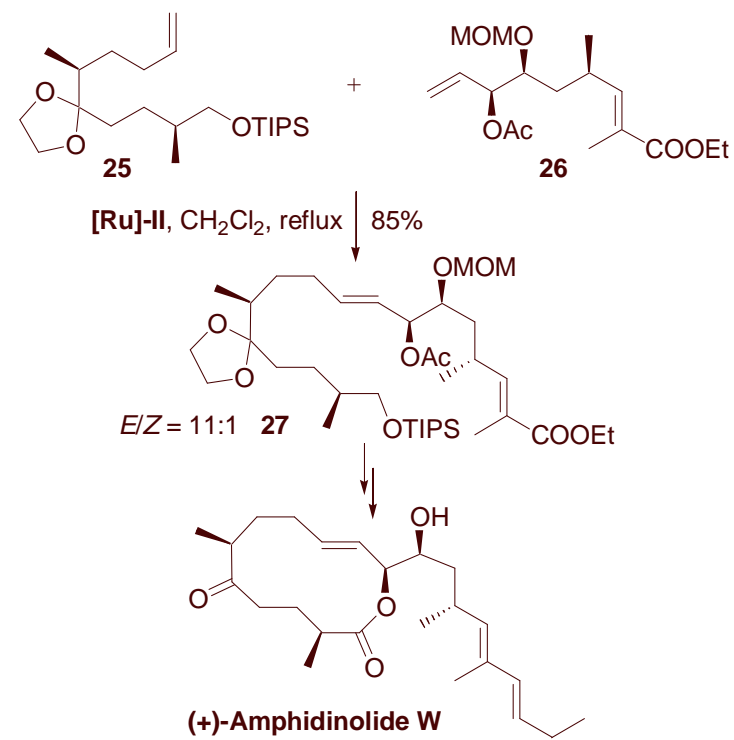

Scheme 8. Synthesis of (+)-amphidinolide W. 
Finally, fragment coupling was effected by cross-metathesis during the formal synthesis of FR900848 (which was isolated from Streptovercillium fervens) by Zercher and Verbicky [21]. In a first step, olefin 28 was dimerized in the presence of first-generation Grubbs catalyst [Ru]-I to give $\mathbf{2 9}$ in $64 \%$ yield with an 11.3:1 E/Z ratio (Scheme 9). This homodimer was then coupled with alkene 30 under the same conditions to provide compound $\mathbf{3 1}$ in good yield but with a modest stereoselectivity. The authors do not mention if direct coupling of $\mathbf{2 8}$ and $\mathbf{3 0}$ was attempted. The tactical use of dimers of primary olefins in CM was studied the same year by Grubbs [5], and he showed that homodimerization of the other coupling partner is negligible. Hydrolysis of the benzoate ester $(\mathrm{Bz})$ led to 32, which was transformed by Barrett into antifungal agent FR-900848 [22].

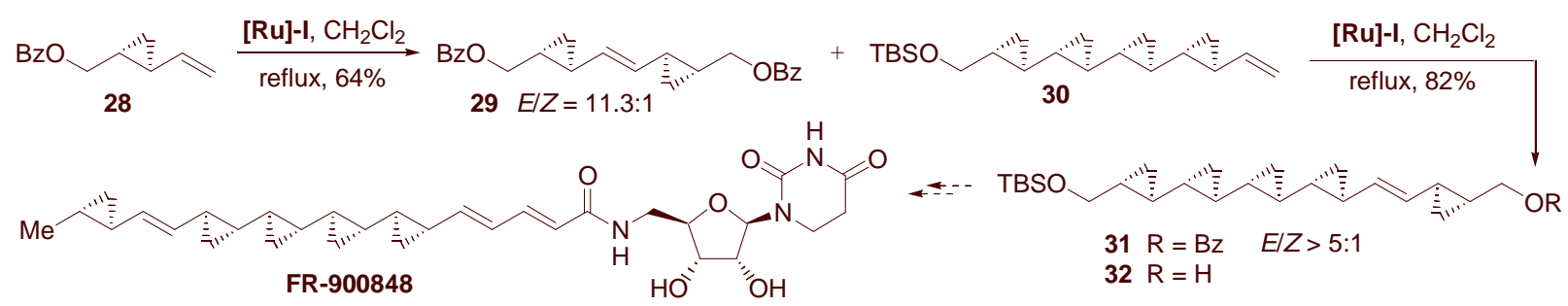

Scheme 9. Formal synthesis of FR-900848.

1,1-Disubstitued alkenes do not usually dimerize in the presence of catalyst [Ru]-II, but when isobutylene was used as solvent in CM, a small amount of back-ground dimerization was observed. Grubbs reported the superior behavior of 2-methyl-2-butene for this kind of reactions [23], and Stoltz employed this reagent the synthesis of the bicylo[3.3.1]nonane core of garsubellin A, a potential Alzheimer's therapeutic isolated from Garcinia subelliptica [24]. The isoprenyl side chain was installed in good yield from 33 by CM in neat 2-methyl-2-butene with catalyst [Ru]-II (Scheme 10).

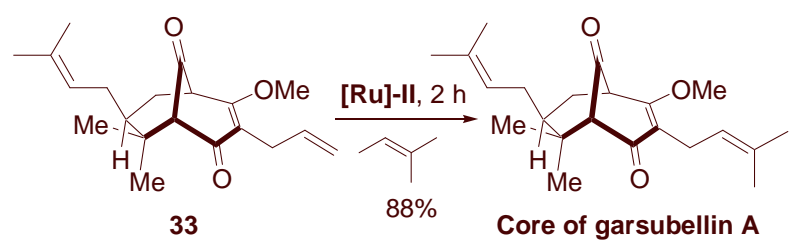

Scheme 10. Synthesis of the core of garsubellin A.

\section{CM leading to an olefin which is reduced in a subsequent step}

Cross-methesis reaction followed by reduction of the resulting alkene is a very convenient way of making a $\mathrm{C}-\mathrm{C}$ bond bearing no functional group. Moreover, the question of stereoselectivity, which is not always very high in CM reactions, is not an issue any more. The most common mean of reduction for this sequence is catalytic hydrogenation.

CM with acrylic acid followed by hydrogenation was employed for the construction of (-)centrolobine, an antiprotozoal product isolated from the heartwood of Centrolobium robustum and the stem of Brosinium potabile [25]. In this case, cross-metathesis and hydrogenation were effected in one pot, with lactonization and hydrogenolysis of the benzyl protecting group as additional transformations to produce 35 in 56\% overall yield (Scheme 11). 


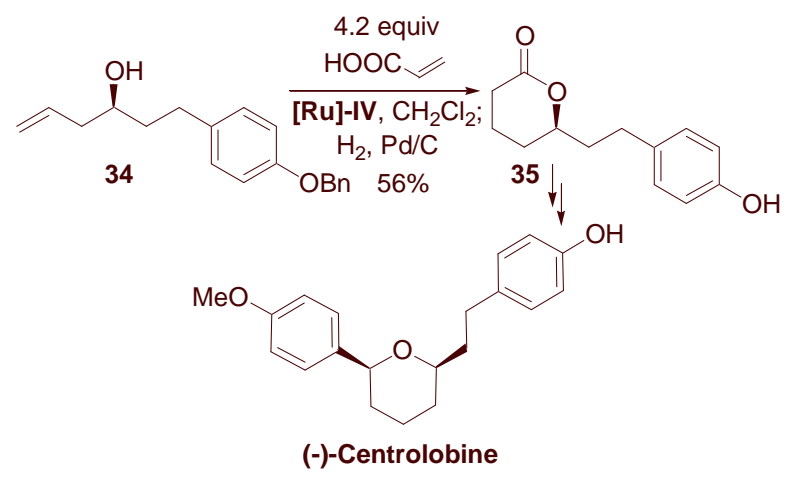

Scheme 11 Synthesis of (-)-centrolobine.

Blechert and co-workers synthesized piperidine and pyrrolidine alkaloids using CM with conjugated ketones. The backbone of these compounds was assembled by $\mathrm{CM}$, and cyclization was effected by concomitant reduction of the olefin and reductive amination of the resulting saturated amino ketone (Scheme 12). Carpamic acid was thus obtained from compounds $\mathbf{3 6 b}$ and $\mathbf{3 7}$ in excellent overall yield [26]. If the metathesis step was performed with 36a, the yield was less than $60 \%$ because of competing homodimerization of this compound. With the more hindered TMS analogue $\mathbf{3 6 b}$, homodimerization was almost completely suppressed. The same group also published the synthesis of xenovenine, isolated from the thief ant Solenopsis xenovenum, and indolizidine 209B, a potent neurotransmitter exuded by the skin of neotropical dendrobatid frogs, by a $\mathrm{CM} /$ double reductive cyclization sequence (Scheme 12) [27].

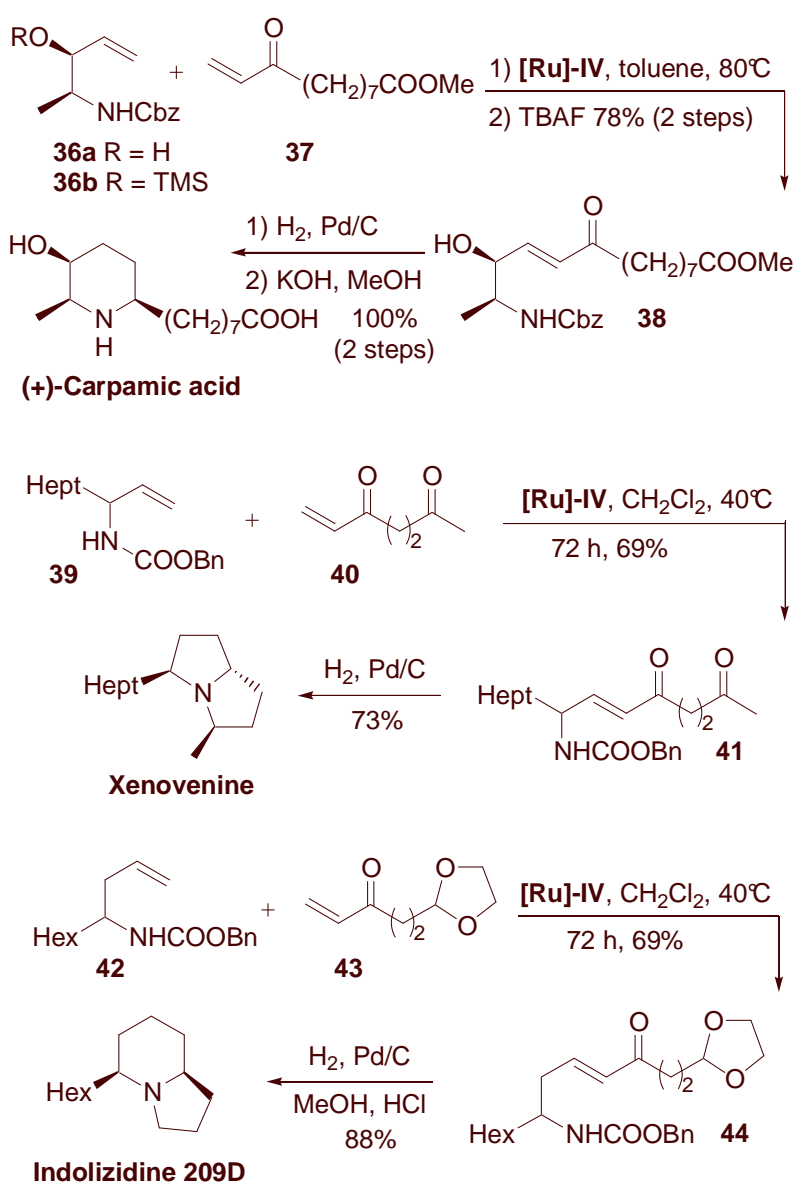

Scheme 12. Syntheses of piperidine and pyrrolidine alkaloids with a CM/reductive cyclization sequence. 
In the case of indolizidine 209B, hydrogenation under acidic conditions effected four steps in one pot: cleavage of the nitrogen protecting group, deprotection of the acetal and two reductive cyclizations in $88 \%$ yield.

Cossy et al. employed a CM reaction with a terminal olefin followed by hydrogenation for the construction of the side chain of (-)-prosophylline, an alkaloid extracted from the leaves of Prosopis africana which possesses interesting antibiotic and anesthetic properties [28]. The same group reported the synthesis of (+)-preussin, an alkaloid isolated from Aspergillus ochraceus which displays antifungal and antibacterial activities [29]. The metathesis/hydrogenation reactions were used for the construction of the linear precursor of the target compound, and ring closing was effected by substitution of the bismesylate derived from 46 by methylamine (Scheme 13). Deprotection of the methoxymethyl (MOM) group under acidic conditions led to $(+)$-preussin in good overall yield. For this compound, the side chain was introduced before the cyclization reaction. In both syntheses, the metathesis reactions were not stereoselective, as it is usually the case for CM between terminal alkenes.

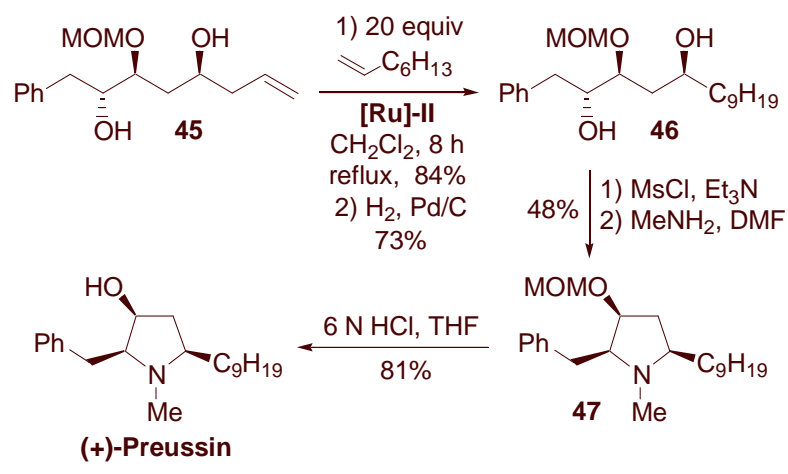

Scheme 13. Synthesis of (+)-preussin using a CM/hydrogenation sequence.

Kim and co-workers recently described the syntheses of (-)-antofine and (-)-cryptopleurine [30]. The former exhibits activity against multi-drug resistant cancer cell-lines. The structures of these alkaloids only differ by the size of one ring, pyrrolidine for (-)-antofine and piperidine for (-)cryptopleurine (Scheme 14). For (-)-antofine, the five-membered ring is efficiently formed by a ringclosing metathesis (RCM) reaction followed by hydrogenation. The same sequence was envisaged for the second synthesis, but homoallylation of $48 \mathrm{a}(\mathrm{R}=\mathrm{Me})$ could not be achieved. The authors instead resorted to a $\mathrm{CM}$ reaction to construct the (-)-cryptopleurine backbone. Reaction of $\mathbf{4 8 b}(\mathrm{R}=\mathrm{H})$ with homoallyl acetate $\mathbf{4 9}$ in the presence of second-generation Grubbs catalyst [Ru]-II only produced 38\% of $\mathbf{5 1}$ as a 4:1 mixture of $E / Z$ olefin isomers, along with $54 \%$ of recovered starting material. Use of the corresponding dimer 50 improved the yield to $82 \%$ (14\% of $\mathbf{4 8 b}$ was recovered as well) and the selectivity to $8: 1$. This is another example of the superior behavior of dimers of primary olefins in CM [5]. Simultaneous hydrogenation of the double bond and of the benzyloxycarbonyl (Cbz) protecting group, followed by saponification of the acetate led to the saturated amino alcohol, which was cyclized under Mitsunobu conditions to produce 52. Stirring this compound with formaldehyde and $\mathrm{HCl}$ in ethanol at reflux then furnished (-)-cryptopleurine.

The zaragozic acids, fungal metabolites isolated by researchers from Merck, are inhibitors of squalene synthase, which makes them potent hypocholestemic agents. Hashimoto used a $\mathrm{CM} /$ hydrogenation sequence to install the $\mathrm{C} 1$ side chain of zaragozic acid $\mathrm{C}$ (Scheme 15) [31]. Complex [Ru]-II catalyzed the formation of compound $\mathbf{5 5}$ in 67\% yield. Starting alkenes $\mathbf{5 3}$ and $\mathbf{5 4}$ (which is used in only slight excess) were recovered in $10 \%$ and $24 \%$ yield respectively. The new double bond was then hydrogenated in the presence of $\mathrm{Pd} / \mathrm{BaSO}_{4}$. 


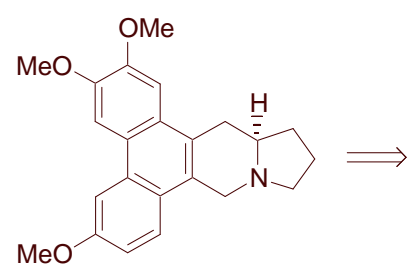

(-)-Antofine

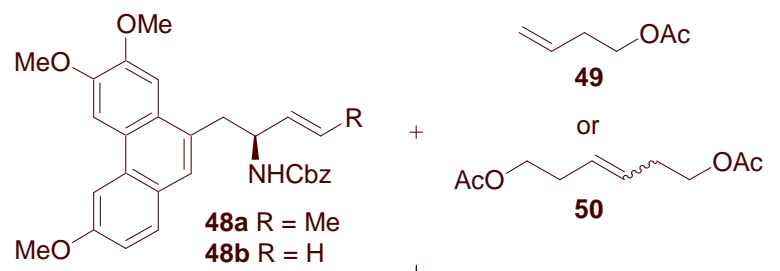

[Ru]-II $\mid \mathrm{CH}_{2} \mathrm{Cl}_{2}$, reflux, $24 \mathrm{~h}$

1) $\mathrm{H}_{2}, \mathrm{Pd} / \mathrm{C}, 95 \%$

2) $5 \mathrm{~N} \mathrm{NaOH}, 90 \%$

3) $\mathrm{DIAD}, \mathrm{PPh}_{3}, 68 \%$

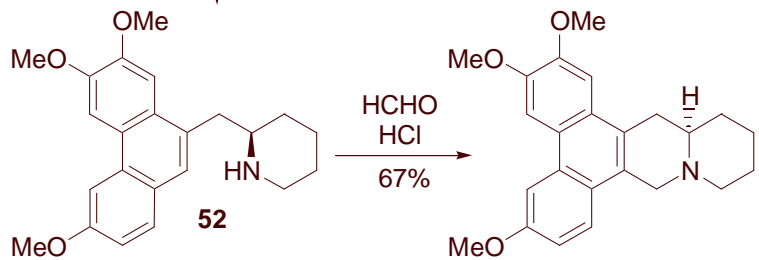

(-)-Cryptopleurine

Scheme 14. Synthetic strategies for (-)-antofine and (-)-cryptopleurine.

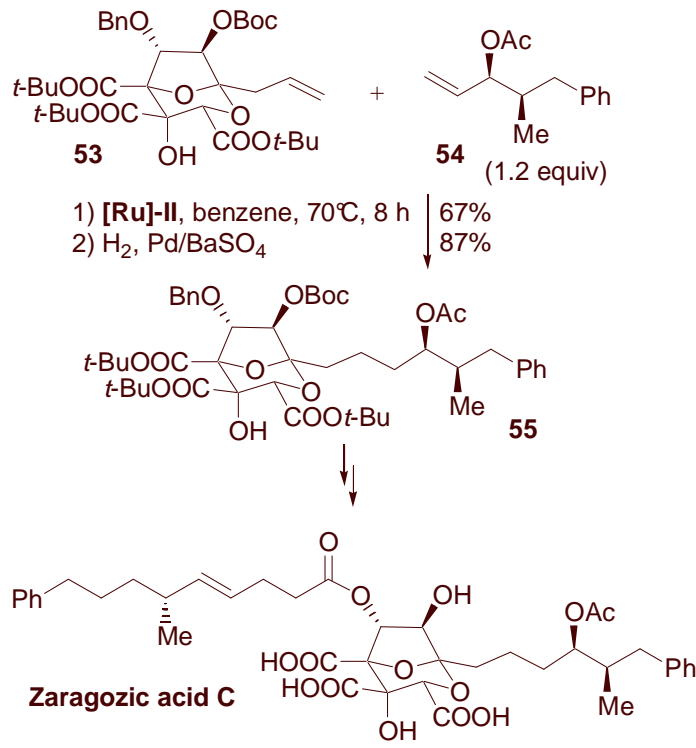

Scheme 15. Synthesis of the $\mathrm{C} 1$ side chain of zarogozic acid C.

Ghosh and Liu employed the same sequence to assemble the skeleton of the C1-C10 fragment of (+)-amphidinolide T1, an antitumor agent isolated from the marine dinoflagellates Amphidinium sp 
(Scheme 16) [32]. Reaction of $\mathbf{5 6}$ and $\mathbf{5 7}$ under Grubbs' second-generation conditions ([Ru]-II) gave the desired cross-metathesis product $\mathbf{5 8}$ in $60 \%$ yield, along with the homodimers of both coupling partners. These dimers could be separated and recycled with another loading of catalyst [Ru]-II to furnish an additional $36 \%$ yield of $\mathbf{5 8}$, bringing the total yield of the metathesis step to $96 \%$ after two cycles. The $1: 1$ mixture of olefin isomers was then hydrogenated to furnish $\mathbf{5 9}$ in $98 \%$ yield.

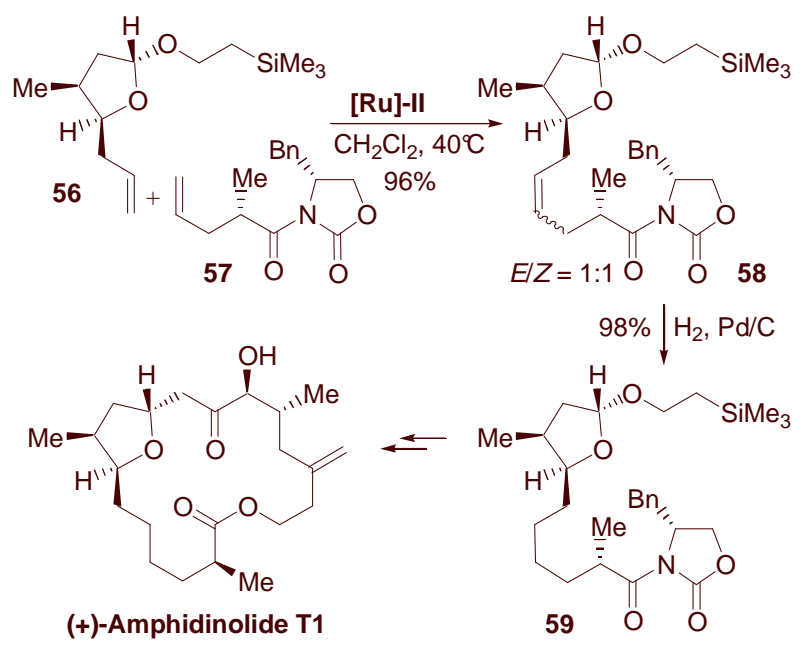

Scheme 16. Synthesis of amphidinolide T1.

Wipf and his group converted an allyl substituent into an ethyl group during their synthesis of (-)tuberostemonine (Scheme 17) [33], a compound from the family of the Stemona alkaloids, which have been used against tuberculosis and bronchitis in Eastern folk medicine. Isomerization of the terminal double bond in 60 was accomplished with catalyst [Ru]-II in toluene at reflux in the presence of allyltritylamine and diisopropylethylamine (DIPEA) [34]. CM reaction of 61 with ethylene in the presence of catalyst [Ru]-IV and para-toluenesulfonic acid (TsOH) in dichloromethane at reflux furnished compound $\mathbf{6 2}$ in $81 \%$ yield. Use of the phosphine-free catalyst for this step was important to avoid lengthy chromatographic separation that led to decomposition of the product. Simple hydrogenation of the vinyl substituent provided (-)-tuberostemonine in excellent yield.

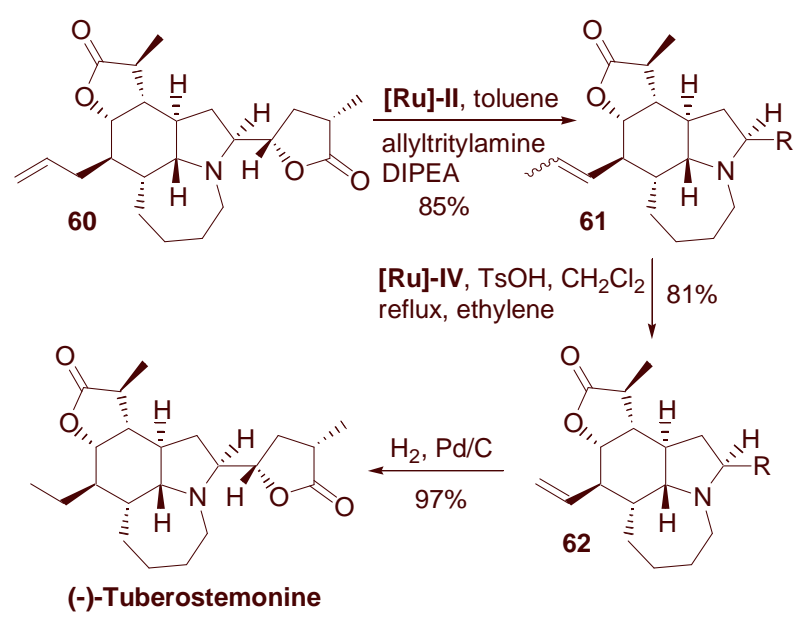

Scheme 17. Transformation of an allyl substituent into an ethyl group during the synthesis of (-)tuberostemonine.

Several syntheses of polyether compounds reported in the last five years involve a CM step. Bullatanocin, an acetogenin isolated from the bark of Annona bullata, was found to be identical to 
squamostatin $\mathrm{C}$, previously extracted from the seeds of Annona squamosa. This product exhibits activity against the colon cell line HT-29 and the lung cell line A-549 and is over 10000 times more active than adriamycin. The cross-metathesis step involved in its synthesis by Mootoo proceeds in 98\% yield (based on $86 \%$ conversion of $\mathbf{6 3}$ ) if allylic acetate $\mathbf{6 4}$ is used in a 4-fold excess with catalyst [Ru]-II (Scheme 18) $[35]$.

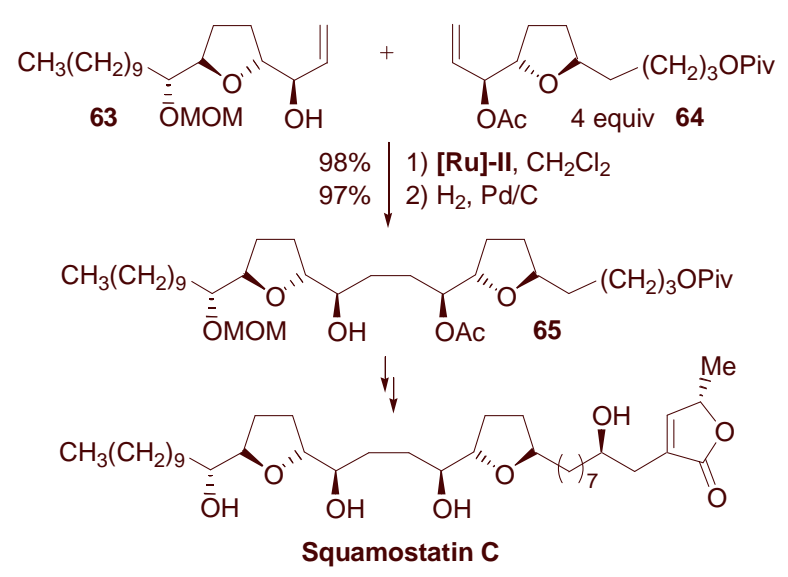

Scheme 18. Syntheses of squamostatin C.

Diimide was also used for the reduction step following the CM reaction. McDonald and Wei reported a formal synthesis of thyrsiferol and venustatriol [36]. Fragment coupling of vinyl epoxides 66 and 67 (3 equiv) furnished the desired compound 68 in only 40\% yield, along with the homodimer of 66 and unreacted 66 (Scheme 19). The total yield was increased to 64\% when the mixture of the homodimer of 66 and recovered 66 was resubmitted to ruthenium catalyst [Ru]-II in the presence of additional 67. Formation of the tetrahydropyran B-ring was accomplished by treatment of epoxy alcohol 69 with a catalytic amount of pyridinium para-toluenesulfonate (PPTS). The olefin formed by CM was reduced with diimide, formed in situ from hydrazine and hydrogen peroxide, and the last tetrahydropyran was obtained by cyclization of epoxy alcohol 71 with titanium tetraisopropoxide $\left(\mathrm{Ti}(\mathrm{O} i-\mathrm{Pr})_{4}\right)$.
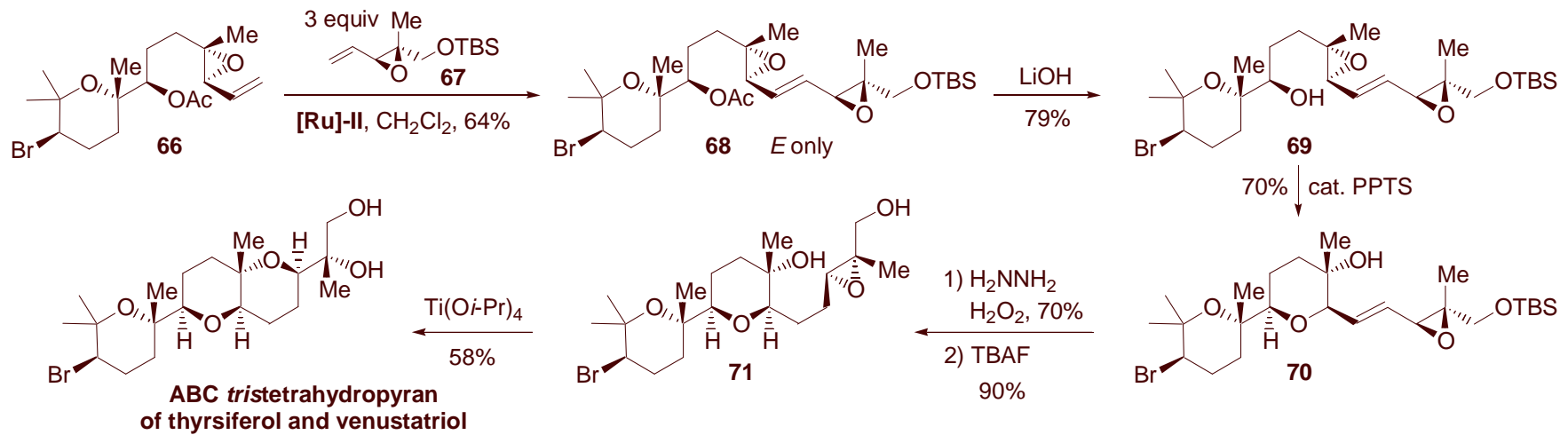

Scheme 19. Synthesis of the tristetrahydropyran substructure of thyrsiferol and venustatriol.

A diastereomer of glabrescol, a novel polytetrahydrofuranic squalenoid isolated from the Caribbean plant Spathelia glabrescens, was synthesized by Xiong and Corey with the help of olefin cross-metathesis [37]. The same authors then reported the synthesis of the natural product by another route [38]. Dimerization of $\mathbf{7 2}$ was performed in the presence of first-generation Grubbs catalyst [Ru]-I to give the desired product as the $E$-isomer only (Scheme 20). The disubstituted olefin was then selectively reduced with diimide, formed in situ from potassium azodicarboxylate and acetic acid, to furnish 
compound 74 in 50\% overall yield. The remainining steps to $\mathbf{7 5}$ include asymmetric dihydroxylation of one of the end double-bond [39], Shi epoxidation of the other alkenes [40], and cascade cyclizations catalyzed by camphorsulfonic acid (CSA).

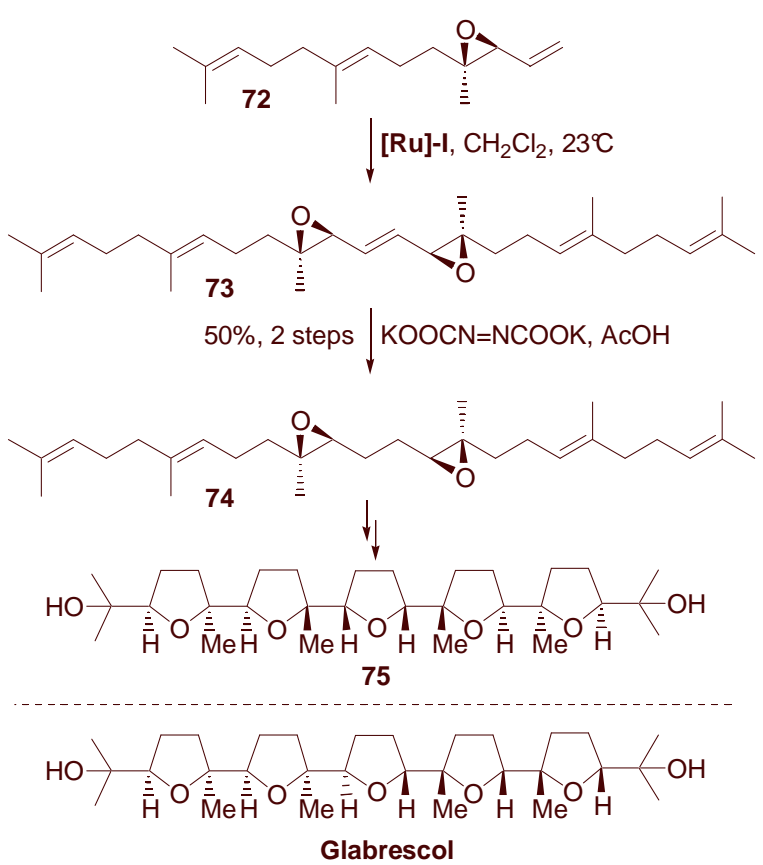

Scheme 20. Synthesis of a diasteromer of squalenoid glabrescol.

\section{CM leading to an olefin which is engaged in other transformations than reduction}

We have seen that a common reaction of the olefin obtained by cross-metathesis is reduction, but there are several examples where this alkene is engaged in other transformations. In their synthesis of aureothin, a compound with antitumor, antifungal and pesticidal activities found in the mycelia of several actinomycetes, Baldwin and his group utilized a CM reaction to convert a geminal olefin into a vinyl boronate, which was then reacted with a vinyl dibromide in a Suzuki coupling [41]. CM of of vinyl boronates and 1,1-disubstituted olefins had already been reported by Grubbs and co-workers [42]. In the present case, the yield was excellent, but the selectivity poor, slightly in favor of the Z-isomer (Scheme 21). The following cross-coupling reaction was performed in the presence of thallium ethoxide (TlOEt) to avoid the formation of side products (the corresponding alkyne and the bis-coupled product).

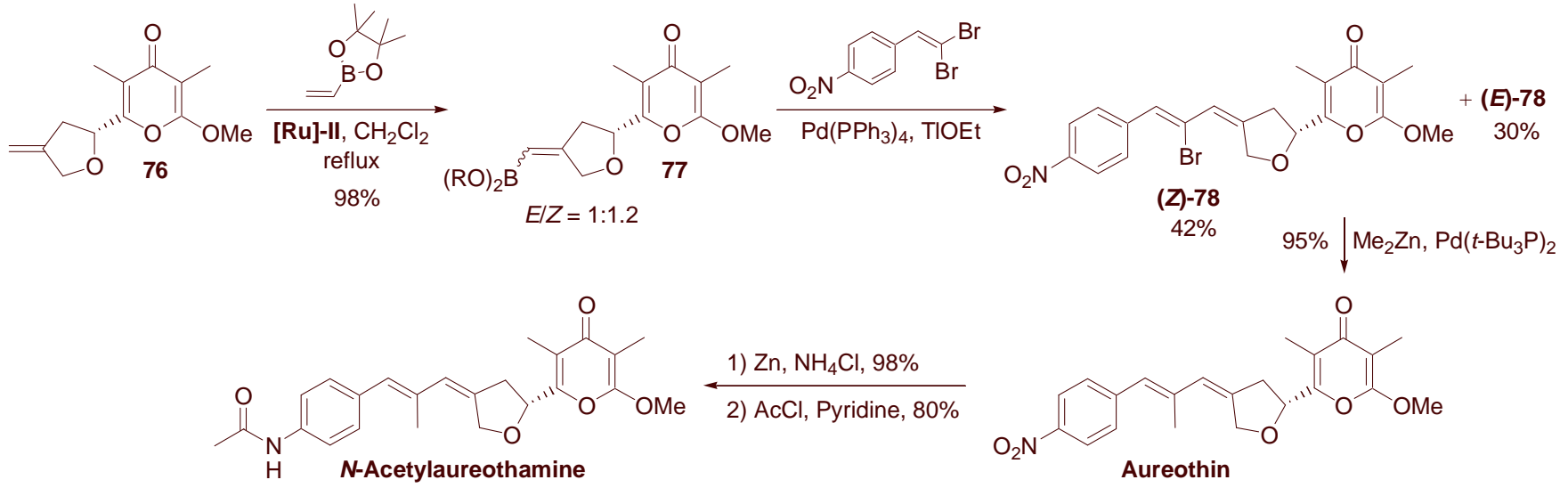

Scheme 21. Preparation of a vinyl boronate by CM in the course of the synthesis of aureothin. 
The olefin isomers were separated and $(\boldsymbol{Z}) \mathbf{- 7 8}$ was reacted with dimethylzinc under palladium catalysis to furnish aureothin in good yield. A parent compound, $N$-acetylaureothamine, was also synthesized in two steps from aureothin. This product was isolated from Streptomyces netropsis, and is very effective against chronic gastritis.

Roush et al. functionalized a homoallylic alcohol with a terminal olefin by coupling it with methyl acrylate [43]. The cross-metathesis of $\mathbf{7 9}$ with catalyst [Ru]-IV proceeded in excellent yield to give $\mathbf{8 0}$ as the $E$-isomer only (Scheme 22) [44]. This compound was then reacted with benzaldehyde and a catalytic amount of potatssium tert-butoxide $(t$-BuOK) according to the method reported by Evans and GauchetPrunet [45] to furnish the syn diol protected as a benzylidene acetal as a single diastereomer.

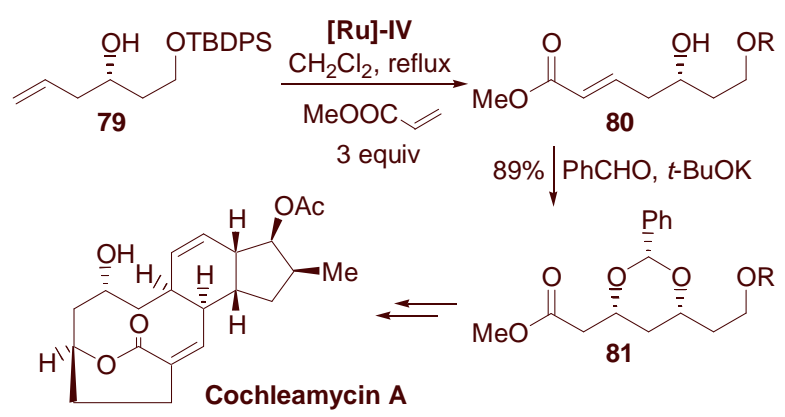

Scheme 22. Functionalization of a homoallylic alcohol en route cochleamycin A.

Allylsilanes undergo additions to electrophiles when activated by a Lewis acid. Recently, three different groups have used CM reactions to prepare highly functionalized allylsilanes which were then transformed into bioactive natural products. Wang and Romo reported the synthesis of (+)-brefeldin A, which exhibits antitumor, antifungal, antimitotic, and immunosuppressive activities (Scheme 23) [46]. Cross-metathesis of compound $\mathbf{8 2}$ with allyltrimethylsilane in the presence of complex [Ru]-II furnished allylsilane $\mathbf{8 3}$ in good yield as a 3:1 mixture of $E / Z$-isomers. This mixture was reacted with titanium tetrachloride $\left(\mathrm{TiCl}_{4}\right)$, and cyclization of the allylsilane moiety onto the $\beta$-lactone with inversion of configuration at the $\beta$ center led to trans-fused cyclopentane 84 as a single diastereomer.

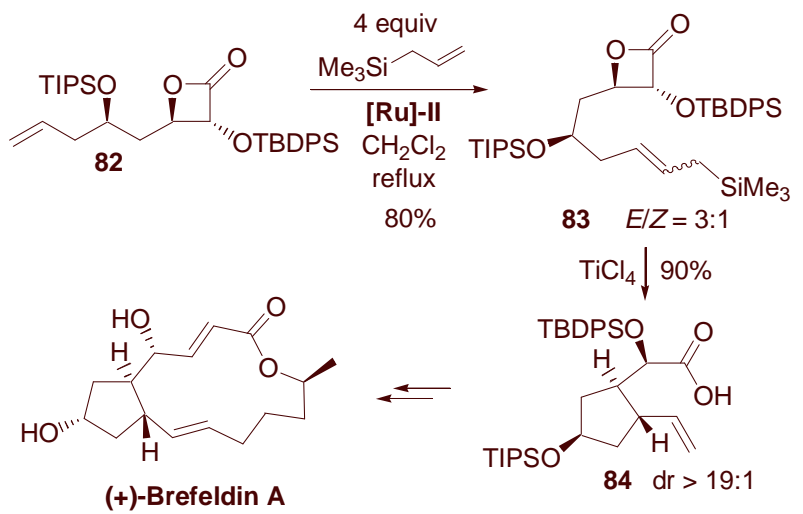

Scheme 23. Allylsilane in the synthesis of (+)-brefeldin A.

Another example of this strategy is found in the synthesis of the (-)-lemonomycin core by Fukuyama and co-workers [47]. This tetrahydroisoquinolidine alkaloid isolated from Streptomyces candidus (LL-AP191) displays interesting antibiotic activity against methicillin-resistant Staphylococcus aurea (MRSA) and vancomycin-resistant Enterococcus faecium (VREF), as well as cytotoxicity against the human colon tumor cell line HCT-116. CM proceeded uneventfully with catalyst [Ru]-II to furnish 
cyclization precursor 86 in 51\% yield. Treatment of this compound with boron trifluoride etherate $\left(\mathrm{BF}_{3} . \mathrm{OEt}_{2}\right)$ effected cyclization via the conjugate acyliminium cation resulting from loss of the acetate group, and $\mathbf{8 7}$ was obtained with complete stereoselectivity (Scheme 24).

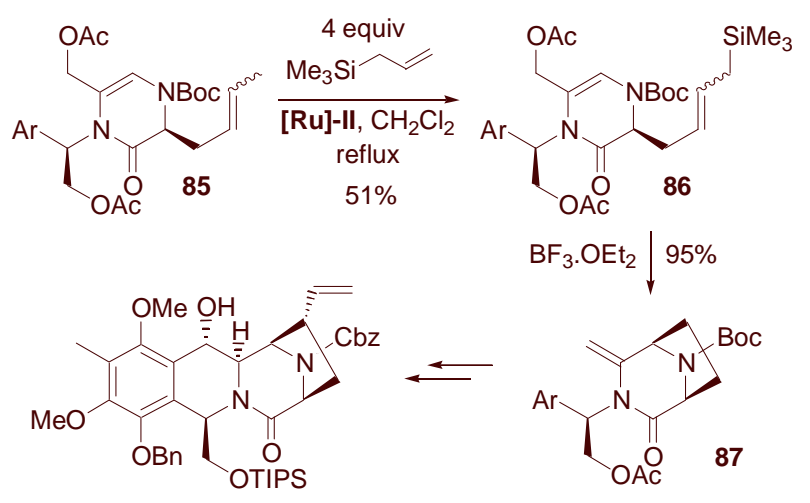

(-)-Lemonomycin core

Scheme 24. Allylsilane in the synthesis of the (-)-lemonomycin core.

The formal synthesis of (+)-anatoxin-a by Kanaza and co-workers constitutes the most recent application of this sequence of reactions (Scheme 25) [48]. This alkaloid, extracted from strains of the fresh-water blue-green alga Anabaena flos aquae (Lyngb.) de Bréb, is one of the most potent agonists of the nicotinic acetylcholine receptor $\mathrm{nAChR}$. The cross-methathesis reaction catalyzed by complex [Ru]II was followed by addition of the allylsilane moiety to the iminium intermediate, which formed the skeleton of the target molecule.
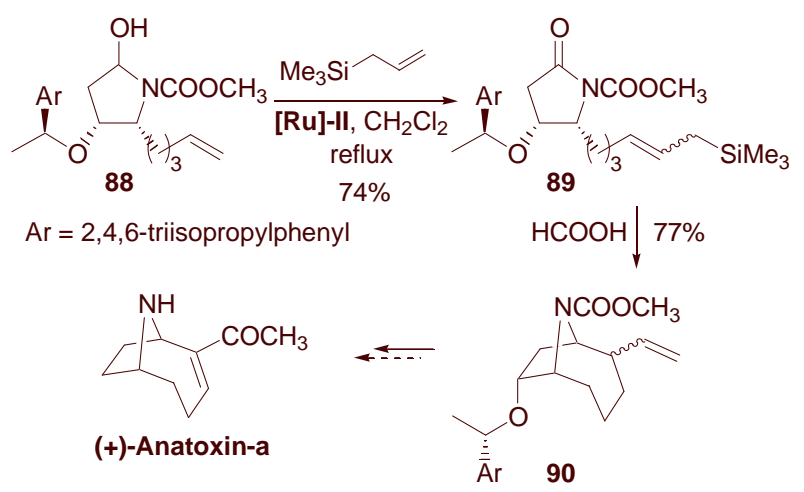

Scheme 25. Formal synthesis of (+)-anatoxin-a.

\section{Tandem processes}

Since olefin metathesis reactions involve alkenes both as starting materials and products, they are potential candidates for cascade and tandem processes. Quinn and co-workers applied this principle to the synthesis of two members of the Annonaceous acetogenin family, (-)-muricatacin, which was extracted from the seeds of Annona muricata [49], and rollicosin, later isolated from Rollinia mucosa [50]. The latter displayed in vitro cytotoxicity against human tumor cell lines. The retrosynthesis envisaged for both compounds include formation of a 5-membered insaturated lactone by RCM, and formation of the side chain by CM of the other alkene in one-pot (Scheme 26). The optimized conditions necessitated slow addition of catalyst [Ru]-II by syringe-pump to a $0.01 \mathrm{M}$ solution of $\mathbf{9 1}$ in dichloromethane at reflux over $8 \mathrm{~h}$. The simple RCM product was observed as an intermediate, confirming that the RCM process is faster 
than the $\mathrm{CM}$ reaction. Interestingly, the other possible RCM product (the 6-membered unsaturated lactone) was never observed. Hydrogenation of compound 92 reduced both olefins and deprotected the benzyl ether to furnish (-)-muricatacin in good yield.

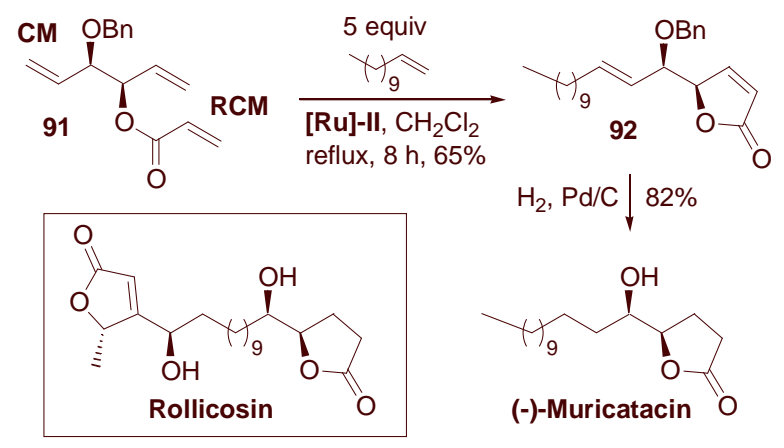

Scheme 26. Syntheses of (-)-muricatacin and rollicosin.

The Smith group reported a very elegant synthesis of cytotoxic agents (-)-cylindrocyclophanes A and $\mathrm{F}$, which were isolated from the terrestrial blue-green algae Cylindrospermum lichenforme [51]. Dimerization of bis-olefin $\mathbf{9 3}$ with first-generation Grubbs catalyst [Ru]-I, followed by ring-closing metathesis of the resulting dimer furnished exclusively the [7,7]-paracyclophane 94 in $61 \%$ yield as a single $E, E$ isomer (Scheme 27). The yield was not improved with catalyst [Ru]-II, but use of Shrock molybdenum catalyst [Mo] (Fig. (1)) [52] gave optimum result (72\% yield). None of the "head-to-head" dimerization products were observed during this reaction. In a very interesting experiment, these dimers, prepared by another route, were independently submitted to catalyst [Mo], and compound 94 was obtained as the exclusive product in each case. The $[8,6]$-cyclophanes were not detected. The dimers probably undergo a cascade of metathesis reactions leading to the most stable product [7,7]paracyclophane 94.

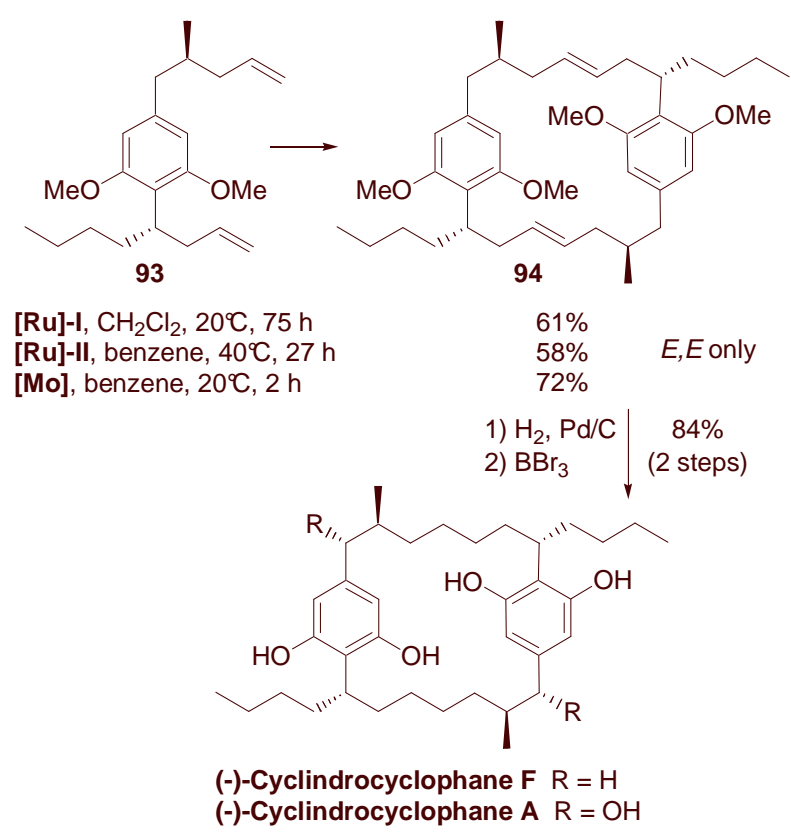

Scheme 27. Synthesis of (-)-cylindrocyclophanes A and F.

Ring-opening metathesis was originally employed for the synthesis of polymers (ROMP), but the ring-opened carbene intermediate can be engaged in CM with a different olefin partner, leading to small 
molecules. Villemin utilized this tandem process in 1984 for the synthesis of triacontanol-1, a very active plant-growth regulator, long before the discovery of the well-known ruthenium and molybdenum catalysts [53]. This expeditious synthesis incorporates a 12-carbon unit into methyl oleate by reaction with cyclododecene in the presence of a catalyctic amount of tungsten(VI) chloride $\left(\mathrm{WCl}_{6}\right)$ and tetramethyl stannane $\left(\mathrm{Me}_{4} \mathrm{Sn}\right)$ (Scheme 28). The ring-closing/double cross-metathesis reaction proceeds in $68 \%$ yield to give compound 95 as a mixture of 4 isomers $(E / Z=1: 3.6$ for both olefins). Triacontanol-1 is then obtained by reduction of the olefins and the methyl ester with lithium aluminum hydride $\left(\mathrm{LiAlH}_{4}\right)$.

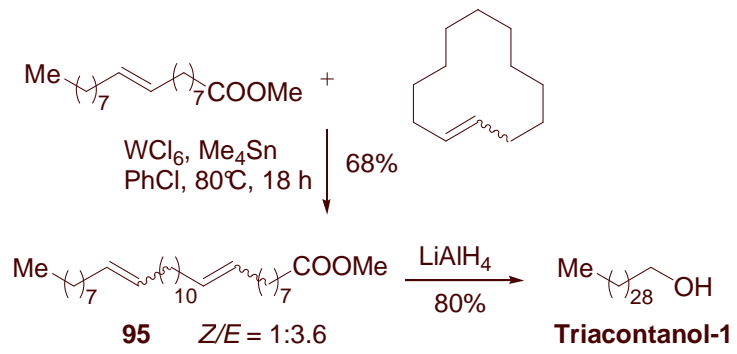

Scheme 28. ROM/CM tandem process in the synthesis of triacontanol-1.

An analogous sequence of reactions is found in the synthesis of the linear center-portion of bistramide A, a marine metabolite isolated from Lissoclinum bistratum which exhibits potent cytotoxicity against severall cell lines, as well as selective activation of a single protein kinase $\mathrm{C}$ isotope $\delta$ (Scheme 29) [54]. Ring-opening of cyclopropene acetal 97 with catalyst [Ru]-II followed by cross-metathesis with alkene 96 produced the elongated acetal, which proved inert to subsequent metathesis. Dienone 98, obtained by acidic hydrolysis of this acetal, was reacted with alkene 99 in a second CM reaction to furnish 100 in $68 \%$ yield.

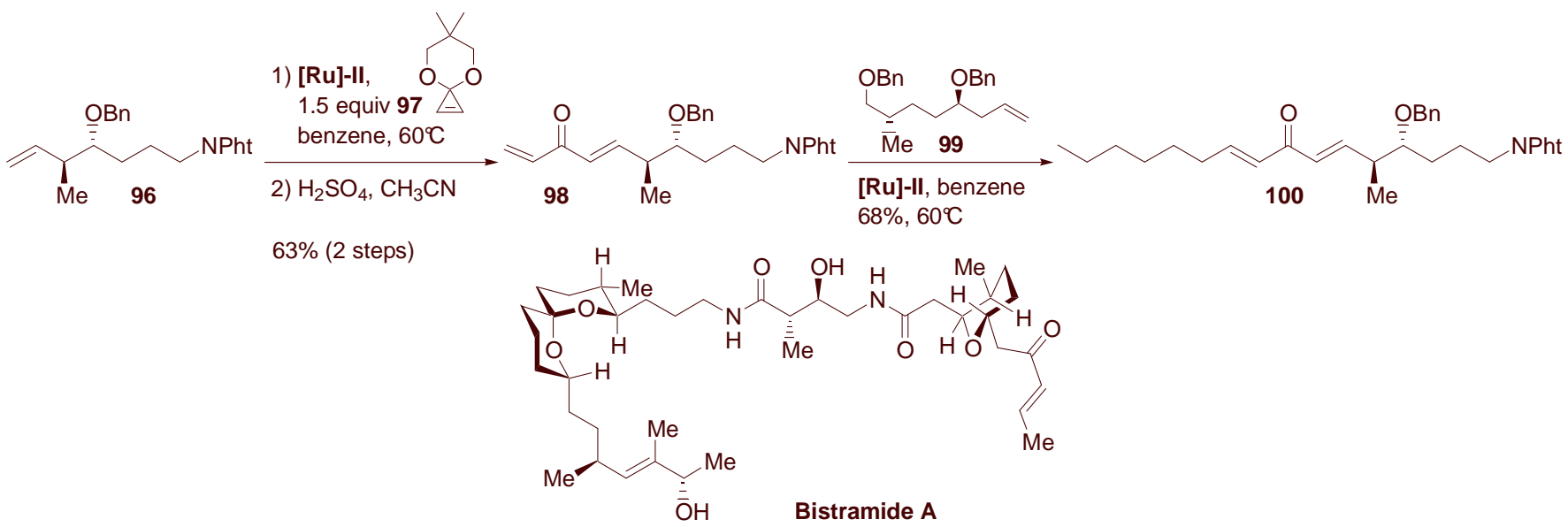

Scheme 29. ROM/CM tandem process in the synthesis of bistramide A.

A three-step process was reported by Tadano and his group for the construction of the 9oxabicyclo[4,2,1]nona-2,4-diene core of $(+)$-mycoepoxydiene, a fungal metabolite whose biological properties have not yet been determined [55]. The reactions were first examined in a step-wise manner. Ring-opening of $\mathbf{1 0 1}$ followed by CM of the carbene intermediates with 1,3-butadiene furnished a mixture of regioisomeric products 102 and $\mathbf{1 0 3}$ (Scheme 30). Since only the $Z$-stereomers can undergo subsequent ring-closure, this reaction was optimized for the formation of the Z-olefins. Catalyst [Ru]-I gave the best ratio, while complex [Ru]-II always favored the $E$-isomers. Formation of cyclooctadiene 104 necessitated the more active catalyst [Ru]-II, so for the one-pot procedure, this carbene was added to the reaction after consumption of $\mathbf{1 0 1}$ and 1,3-butadiene degassing, and the mixture was heated at reflux. 
Desilylation was then effected to enable separation of $\mathbf{1 0 4}$ from the by-products probably resulting from the unproductive $E$-isomers of $\mathbf{1 0 2}$ and $\mathbf{1 0 3}$.

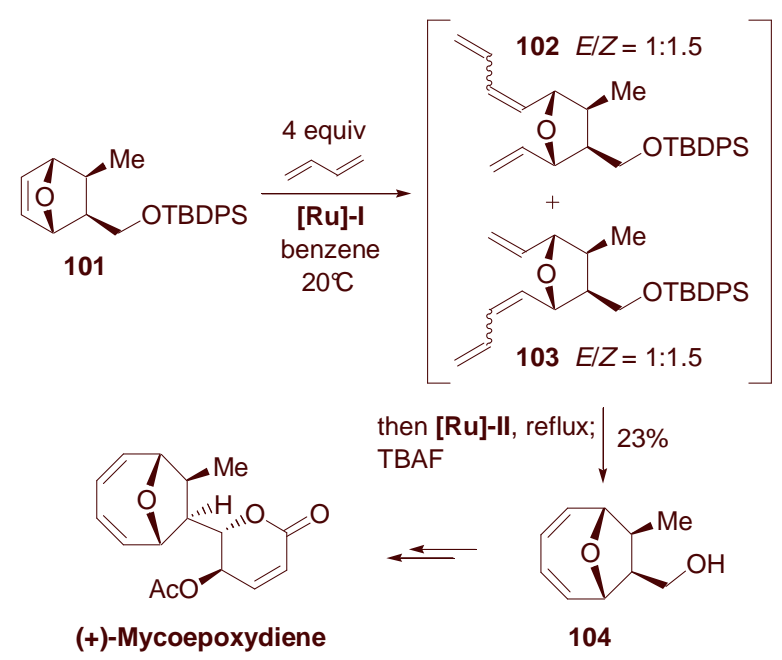

Scheme 30. ROM/CM/RCM process in the synthesis of (+)-mycoepoxydiene.

The key step in the retrosynthesis of (+)-astericanolide, a compound isolated from the odoriferous plant Astericus aquaticus with no known activity, is a tandem ROM/CM/Cope rearrangement [56]. Cyclobutene 105 was ring-opened with catalyst [Ru]-II in benzene at $50^{\circ} \mathrm{C}$ for $10 \mathrm{~h}$, and $\mathrm{CM}$ with ethylene furnished the Claisen rearrangement precursor which was transformed into cyclooctadiene 106 by heating the reaction mixture at reflux for an additional $10 \mathrm{~h}$ (Scheme 31).

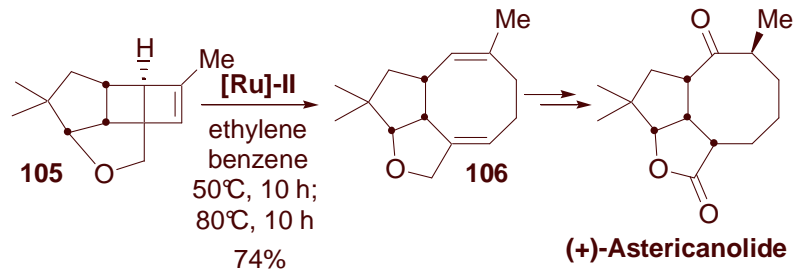

Scheme 31. Tandem ROM/CM/Cope rerrangement in the synthesis of (+)-astericanolide.

A very clever ring-rearrangement followed by cross-metathesis was designed by Zaja and Blechert for the synthesis of (-)-lasubine II, an alkaloid extracted from the leaves of Lagerstroemia subcostata Koehne [57]. Five-membered ring 107 was transformed into cyclohexene 108 by a ROM/RCM sequence, and $\mathrm{CM}$ of a later intermediate $\mathbf{1 0 9}$ with substituted styrene $\mathbf{1 1 0}$ afforded 111, a direct precursor for the reductive cyclization that led to the bicylic structure of (-)-lasubine II (Scheme 32). A one-pot process could be effected starting with cyclopentenone 112, affording compound $\mathbf{1 1 1}$ in $48 \%$ yield. The major side product from this reaction results from direct CM of $\mathbf{1 1 2}$ with styrene $\mathbf{1 1 0 .}$

Finally, metathesis between an alkene and an alkyne, first reported by Mori [58], is a very efficient way of producing 1,3-dienes [59]. The ring-closing version of this reaction (enyne RCM) leads to semi-cyclic 1,3-dienes which can undergo cross-metathesis with another alkene. The one-pot process was first reported by Grimaud et al. [60], and recently used by Clark and co-workers for the construction of polyether substructures found in the dinoflagellates toxins gambierol and hemibrevetoxin B [61]. Hoveyda and his group also employed this sequence of reactions for the synthesis of the antimycobacterial agent erogorgiaene (Scheme 33) [62]. If the enyne metathesis and the CM step with methyl vinyl ketone were realized sequentially, the yields of 114 and 115 were very good. Unfortunately, the yield for the one-pot operation from enyne $\mathbf{1 1 3}$ was never over $20 \%$. 


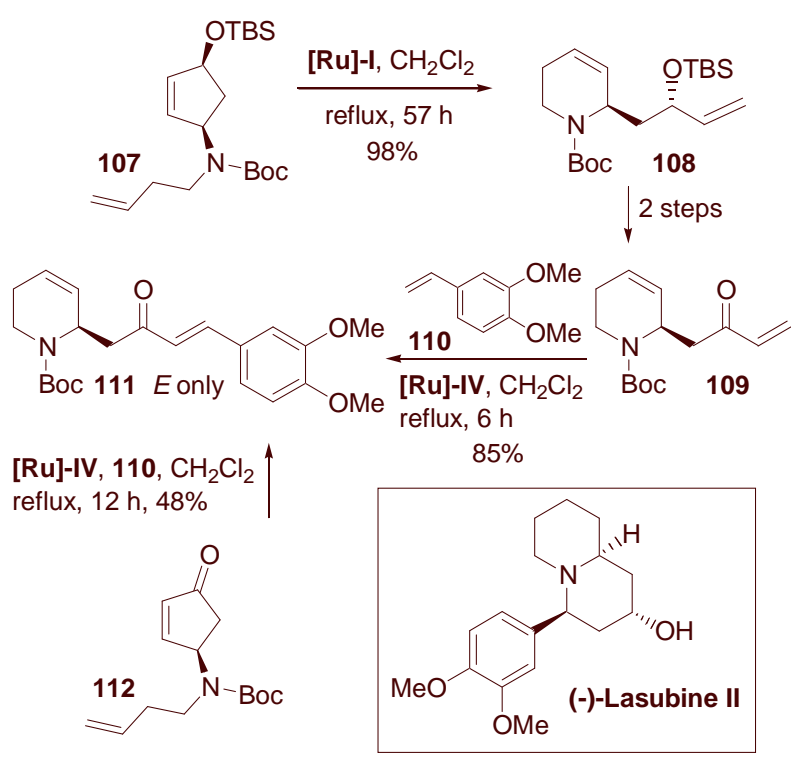

Scheme 32. Tandem ROM/RCM/CM in the synthesis of (-)-lasubine II.

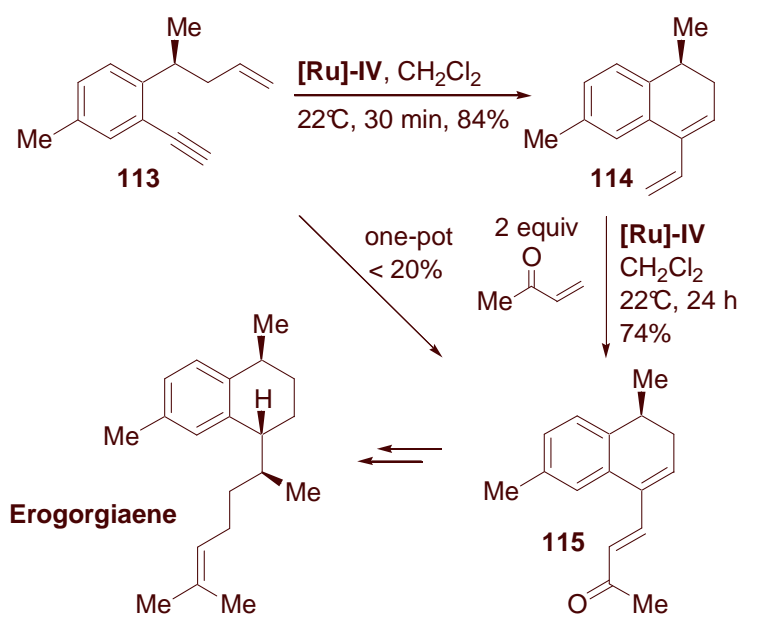

Scheme 33. Synthesis of erogorgiaene using an enyne RCM/CM sequence.

Two other groups performed a CM reaction on a diene that was formed by enyne metathesis, but one or more steps separated the two operations (Scheme 34). A derivative of the antitumor agent $(+)$ anthramycin was synthesized by Mori and co-workers. Grubbs first-generation complex [Ru]-I efficiently catalyzed the formation of five-membered diene 117 [63]. After four steps, the resulting product 118 was submitted to $\mathrm{CM}$ in the presence of ethyl acrylate and [Ru]-IV to furnish compound 119. The diene system could be isomerized into the one present in (+)-anthramycin by heating 119 with rhodium trichloride $\left(\mathrm{RhCl}_{3} \cdot 3 \mathrm{H}_{2} \mathrm{O}\right)$ in ethanol at $110^{\circ} \mathrm{C}$. The synthesis of (-)-dihydroxanthatin was recently reported by Morken et al. (Scheme 34) [64]. The analogous $\alpha$-methylene butyrolactone xanthatin, produced by the same herb Xanthium strumarium, exhibits anti-inflammatory and anti-nociceptive activities, as well as in vivo cytotoxicity against P-388 cell lines. In this case, both enyne RCM and CM were performed with catalyst [Ru]-II and a diastereoselective ( $\mathrm{dr}>20: 1)$ methylation step of butyrolactone 121 intervened between the two metathesis steps. 


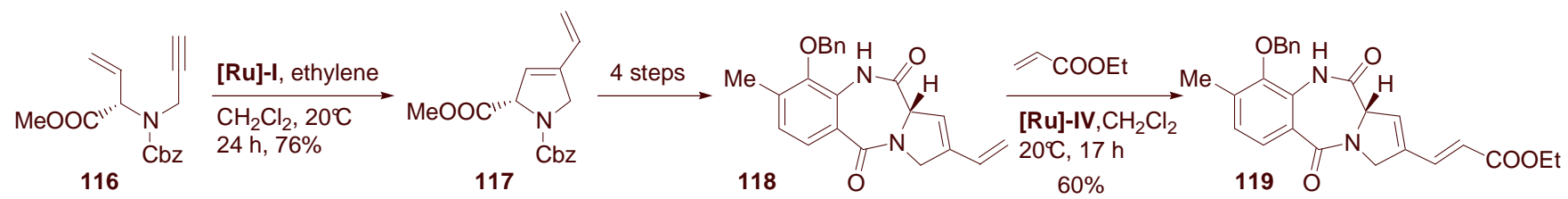

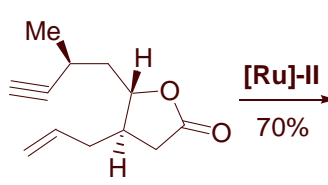

120<smiles>C=CC1=CC[C@H]2CC(=O)O[C@H]2C[C@@H]1C</smiles>

121
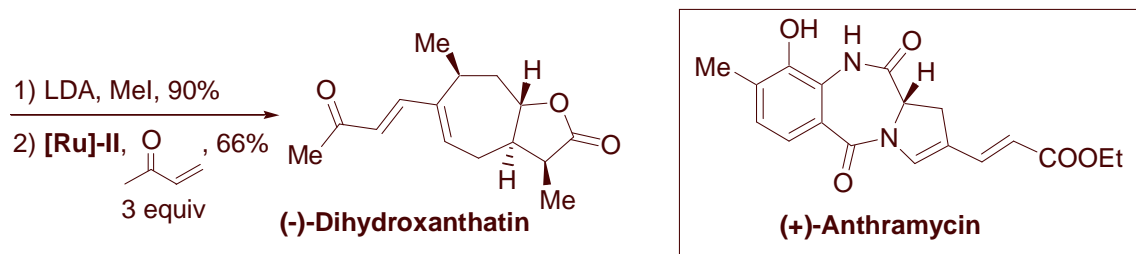

Scheme 34. Syntheses of an (+)-anthramycin derivative and of (-)-dihydroxanthatin.

\section{Conclusion}

Cross-metathesis has been employed in numerous syntheses of bioactive natural products, as well as for the construction of non-natural compounds. Although a late bloomer relative to the parent ringclosing metathesis, this reaction has tremendously benefited from the discovery of the second-generation ruthenium catalysts, and we will undoubtedly see more of its application to synthesis of complex target molecules in the future. 


\section{References}

[1] For general reviews on olefin metathesis, see: Schuster, M.; Blechert, S. Angew. Chem. Int. Ed. 1997, 36, 2036-2056; Fürstner, A. Angew. Chem. Int. Ed. 2000, 39, 3012-3043. For recent reviews on metathesis reactions, see: Prunet, J.; Grimaud, L. One or More $\mathrm{C}=\mathrm{C}$ Bond(s) Formed by Condensation: Condensation of Nonheteroatom-linked Functions, Halides, Chalcogen, or Nitrogen Functions. In Comprehensive Organic Functional Group Transformations II; Katritzky, A. R.; Taylor, R. J. K.; Eds.; Elsevier Pergamon, 2005; Vol 1, pp 669-721; Astruc, D. New J. Chem. 2005, 29, $42-56$.

[2] For reviews on olefin cross-metathesis, see: Gibson, S. E.; Keen, S. P. Top. Organomet. Chem. 1998, 155-188; Connon, S. J.; Blechert, S. Angew. Chem. Int. Ed. 2003, 42, 1900-1923.

[3] Scholl, M.; Ding, S.; Lee C. W.; Grubbs, R. H. Org. Lett. 1999, 1, 953-956.

[4] Garber, S. B.; Kingsbury, J. S.; Gray, B. L.; Hoveyda, A. H. J. Am. Chem. Soc. 2000, 122, 81688179; Gessler, S.; Randl, S.; Blechert, S. Tetrahedron Lett. 2000, 41, 9973-9976.

[5] Chatterjee, A. K.; Choi, T.-L.; Sanders, D. P.; Grubbs, R. H. J. Am. Chem. Soc. 2003, 125, 1136011370; Blackwell, H. E.; O’Leary, D. J.; Chatterjee, A. K.; Washenfelder, R. A.; Bussmann, D. A.; Grubbs, R. H. J. Am. Chem. Soc. 2000, 122, 58-71.

[6] Trost, B. M.; Thiel, O. R.; Tsui, H.-C. J. Am. Chem. Soc. 2003, 125, 13155-13164.

[7] BouzBouz, S.; Cossy, J. Org. Lett. 2001, 3, 1451-1454.

[8] Hafner, A.; Duthaler, R. O.; Marti, R.; Rihs, G.; Rothe-Streit, P.; Schwarzenbach, F. J. Am. Chem. Soc. 1992, 114, 2321-2336.

[9] BouzBouz, S.; Cossy, J. Org. Lett. 2004, 6, 3469-3472.

[10] BouzBouz, S.; de Lemos, E.; Cossy, J.; Saez, J.; Franck, X.; Figadère, B. Tetrahedron Lett. 2004, 45, 2615-2617.

[11] Lautens, M.; Maddess, M. L. Org. Lett. 2004, 6, 1883-1886.

[12] Torsell, S.; Somfai, P. Org. Biomol. Chem. 2004, 2, 1643-1646.

[13] Rai, A. N.; Basu, A. Org. Lett. 2004, 6, 2861-2863.

[14] Hasegawa, H.; Yamamoto, T.; Hatano, S.; Hakogi, T.; Katsumura, S. Chem. Lett. 2004, 33, 15921593.

[15] Love, J. A.; Morgan, J. P.; Trnka; T. M.; Grubbs, R. H. Angew. Chem. Int. Ed. 2002, 41, $4035-$ 4037.

[16] Sarabia, F.; Sánchez-Ruiz, A. Tetrahedron Lett. 2005, 46, 1131-1135.

[17] Oguri, H.; Sasaki, S.-y.; Oishi, T.; Hirama, M. Tetrahedron Lett. 1999, 40, 5405-5408.

[18] Nguyen, S. T.; Grubbs, R. H. J. Am. Chem. Soc. 1993, 115, 9858-9859; Schwab, P.; France, M. B.; Ziller, J. W.; Grubbs, R. H. Angew. Chem. Int. Ed. 1995, 34, 2039-2041; Schwab, P.; Grubbs, R. H.; Ziller, J. W. J. Am. Chem. Soc. 1996, 118, 100-110.

[19] Nicolaou, K. C.; Vyskocil, S.; Koftis, T. V.; Yamada, Y. M. A.; Ling, T.; Chen, D. Y.-K.; Tang, W.; Petrovic, G.; Frederick, M. O.; Li, Y.; Satake, M. S. Angew. Chem. Int. Ed. 2004, 43, 4312-4318; Nicolaou, K. C.; Koftis, T. V.; Vyskocil, S.; Petrovic, G.; Ling, T.; Yamada, Y. M. A.; Tang, W.; Frederick, M. O. Angew. Chem. Int. Ed. 2004, 43, 4318-4324.

[20] Ghosh, A. K.; Gong, G. J. Am. Chem. Soc. 2004, 126, 3704-3705.

[21] Verbicky, C. A.; Zercher, C. K. Tetrahedron Lett. 2000, 41, 8723-8727.

[22] Barrett, A. G. M.; Kasdorf, K. J. Am. Chem. Soc. 1996, 118, 11030-11037.

[23] Chaterjee, A. K.; Sanders, D. P.; Grubbs, R. H. Org. Lett. 2002, 4, 1939-1942.

[24] Spessard, S. J.; Stoltz, B. M. Org. Lett. 2002, 4, 1943-1946.

[25] Boulard, L.; BouzBouz, S.; Cossy, J.; Franck, X.; Figadère, B. Tetrahedron Lett. 2004, 45, 66036605.

[26] Randl, S.; Blechert, S. Tetrahedron Lett. 2004, 45, 1167-1169.

[27] Gebauer, J.; Dewi, P.; Blechert, S. Tetrahedron Lett. 2005, 46, 43-46. 
[28] Cossy, J.; Willis, C.; Bellosta, V. Synlett 2001, 1578-1580; Cossy, J.; Willis, C.; Bellosta, V.; BouzBouz, S. J. Org. Chem. 2002, 67, 1982-1992.

[29] Canova, S.; Bellosta, V.; Cossy, J. Synlett 2004, 1811-1813.

[30] Kim, S.; Lee, T.; Lee, E.; Lee, J.; Fan, G.-j.; Lee, S. K.; Kim, D. J. Org. Chem. 2004, 69, 31443149.

[31] Nakamura, S.; Hirata, Y.; Kurosaki, T.; Anada, M.; Kataoka, O.; Kitagaki, S.; Hashimoto, S. Angew. Chem. Int. Ed. 2003, 42, 5351-5355.

[32] Ghosh, A.; Liu, C. J. Am. Chem. Soc. 2003, 125, 2374-2375.

[33] Wipf, P.; Rector, S. R.; Takahashi, H. J. Am. Chem. Soc. 2002, 124, 14848-14849.

[34] Hu, Y.-J.; Dominique, R.; Das, K. S.; Roy, R. Can. J. Chem. 2000, 78, 838-845.

[35] Zhu, L.; Mootoo, D. R. Org. Lett. 2003, 5, 3475-3478; Zhu, L.; Mootoo, D. R. J. Org. Chem. 2004, 69, 3154-3157.

[36] McDonald, F. E.; Wei, X. Org. Lett. 2002, 4, 593-595.

[37] Xiong, Z.; Corey, E. J. J. Am. Chem. Soc. 2000, 122, 4831-4832.

[38] Xiong, Z.; Corey, E. J. J. Am. Chem. Soc. 2000, 122, 9328-9329.

[39] Corey, E. J.; Noe, M. C.; Lin, S. Tetrahedron Lett. 1995, 36, 8741-8744.

[40] Wang, Z.-X.; Tu, Y.; Frohn, M.; Zhang, J.-R.; Shi, Y. J. Am. Chem. Soc. 1997, 119, 11224-11235.

[41] Jacobsen, M. F.; Moses, J. E.; Adlington, R. M.; Baldwin, J. E. Org. Lett. 2005, 7, 641-644.

[42] Morril, C.; Grubbs, R. H. J. Org. Chem. 2003, 68, 6031-6034.

[43] Cossy, J.; BouzBouz, S.; Hoveyda, A. H. J. Organomet. Chem. 2001, 624, 327-332.

[44] Dineen, T. A.; Roush, W. R. Org. Lett. 2004, 6, 2043-2046.

[45] Evans, D. A.; Gauchet-Prunet, J. A. J. Org. Chem. 1993, 58, 2446-2453.

[46] Wang, Y.; Romo, D. Org. Lett. 2002, 4, 3231-3234.

[47] Rikimaru, K.; Mori, K.; Kan, T.; Fukuyama, T. Chem. Commun. 2005, 394-396.

[48] Neves Muniz, M.; Kanazawa, A.; Greene, A. E. Synlett 2005, 1328-1330.

[49] Quinn, K. J.; Isaacs, A. K.; Arvary, R. A. Org. Lett. 2004, 6, 4143-4145.

[50] Quinn, K. J.; Isaacs, A. K.; De Christopher, B. A.; Szklarz, S. C.; Arvary, R. A. Org. Lett. 2005, 7, 1243-1245.

[51] Smith, III, A. B.; Adams, C. M.; Kozmin, S. A.; Paone, D. V. J. Am. Chem. Soc. 2001, 123, 59255937.

[52] Schrock, R. R.; Murdzek, J. S.; Bazan, G. C.; Robbins, J.; DiMare, M.; O'Reagan, M. J. Am. Chem. Soc. 1990, 112, 3875-3886.

[53] Villemin, D. Tetrahedron Lett. 1983, 24, 2855-2856.

[54] Statsuk, A. V.; Liu, D.; Kozmin, S. A. J. Am. Chem. Soc. 2004, 126, 9546-9547.

[55] Takao, K.-i.; Yasui, H.; Yamamoto, S.; Sasaki, D.; Kawasaki, S.; Watanabe, G.; Tadano, K.-i. J. Org. Chem. 2004, 69, 8789-8795.

[56] Limanto, J.; Snapper, M. L. J. Am. Chem. Soc. 2000, 122, 8071-8072.

[57] Zaja, M.; Blechert, S. Tetrahedron 2004, 60, 9629-9634.

[58] Kinoshita, M.; Mori, M. Synlett 1994, 1020-1022.

[59] For recent reviews on enyne metathesis, see: Poulsen, C. S.; Madsen, R. Synthesis 2003, 1-18; Diver, S. T.; Giessert, A. J. Chem. Rev. 2004, 104, 1317-1382.

[60] Royer, F.; Vilain, C.; Elkaïm, L.; Grimaud, L. Org. Lett. 2003, 5, 2007-2009.

[61] Clark, J. S.; Elustondo, F.; Kimber, M. C. Chem. Commun. 2004, 2470-2471.

[62] Cesati, III, R. R.; de Armas, J.; Hoveyda, A. H. J. Am. Chem. Soc. 2004, 126, 96-101.

[63] Kitamura, T.; Sato, Y.; Mori, M. Tetrahedron 2004, 60, 9649-9657.

[64] Evans, M. A.; Morken, J. P. Org. Lett. 2005, 7, 3371-3373. 
Ac

$\mathrm{Bn}$

Boc

$\mathrm{Bz}$

$\mathrm{Cbz}$

CM

DIAD

DIPEA

Fmoc

Hept

Hex

LDA

MOM

$\mathrm{MsCl}$

$\mathrm{Pd} / \mathrm{C}$

$\mathrm{Pht}$

Piv

PMB

RCM

TBDPS

TBS

TIPS

TMS

$\mathrm{TsOH}$
Acetyl

Benzyl

tert-Butoxycarbonyl

Benzoyl

Benzyloxycarbonyl

Cross-metathesis

Diisopropylazodicarboxylate

Diisopropylethylamine

Fluorenylmethyloxycarbonyl

Heptyl

Hexyl

Lithium diisopropylamide

Methoxymethyl

Methanesulfonyl chloride

Palladium on carbon

Phthalimido

Pivaloyl

para-Methoxybenzyl

Ring-closing metathesis

tert-Butyldiphenylsilyl

tert-Butyldimethylsilyl

Triisopropylsilyl

Trimethylsilyl

para-Toluenesulfonic acid 